\title{
Study of flue gas and steam assisted gravity drainage
}

\author{
WANG Ziji \\ Research Institute of Exploration and Development, Liaohe Oilfield Company, CNPC, Panjin 124010, \\ China \\ wang124114@126.com
}

Keywords: Super heavy oil, SAGD, steam chamber, fuel gas, phase behavior simulation, numerical simulation

Abstract. Flue gas assisted steam gravity drainage technique (SAGP) is a both economic and environmental approach to improve heavy oil reservoir development effect, which can control steam chamber growth, save thermal energy and reduce greenhouse emission. Based on the problems of a pilot SAGD reservoir at Liaohe Oil Field is facing, a robust gas-oil equation of state parameters based on PVT experiment data are constructed using phase behavior simulation method. Then, a typical 1-well-patten heavy oil reservoir model simulation was successfully carried on and revealed several benefits of SAGP. For example, SAGP can reduce steam injection volume and heat loss, lower cap temperature, enhance steam chamber sweep volume and sequestrate the flue gas underground.

\section{Introduction}

Steam gravity drainage is firstly presented by Butler in 1980s and has been widely applied in Canada. During late period of SAGD development, some problems can be challenging, such as distortion of steam chamber, large amount consumption of steam, low oil/gas ration.

Flue gas is a kind of greenhouse gas produced by steam generators mostly used in heavy oil thermal recovery and is generally emitted directly into the atmosphere. In recent years, based on conventional SAGD technique, steam assisted gravity push (SAGP) is operated with gas co-injection (such as nitrogen, carbon dioxide, methane and flue gas) can mitigate both economic and environmental issues especially during late stage of SAGD [1-2].

SAGP is still an immature thermal recovery method in China. During decades of thermal development period, Liaohe Oil Field has gained lots of experiences in SAGD field. D block is a super heavy oil pilot reservoir which is reaching to its late development stage. After more than 10 times of steam cycling and 10 years of SAGD recovery, D block is facing several problems such as low oil/gas ratio, high consumption of heat and high production decline rate [2-3]. In this paper, it is focused on the potential of SAGP method in D block.

\section{Characteristics of steam chamber development stages}

In common, SAGD can be characterized to three stages according to steam chamber development styles [4-5] (Fig 1). In early stage, chamber grows in upright direction until reaching to the top of the cap rock. In the middle stage, chamber grows in horizontal direction with a relatively lower speed along the cap rock with the effect of overburden. In chamber zone, oil is heated by steam which can reduce the oil viscosity. Driven by gravity effect, the heated oil will then permeate down to the production well along the edge of steam chamber and cold oil. With the heating process goes on the steam is also condensing to water at the chamber edge and drains to the production well with hot oil. In the late stage, chamber is moving down to the production well until to the steam channeling which is called invalid steam cycling.

\section{Numerical simulation}

A real 1-well-group model from D block was established and simulated using three types of recovery methods (conventional SAGD, SAGP and steam-alterating-gas SAPG) respectively. 

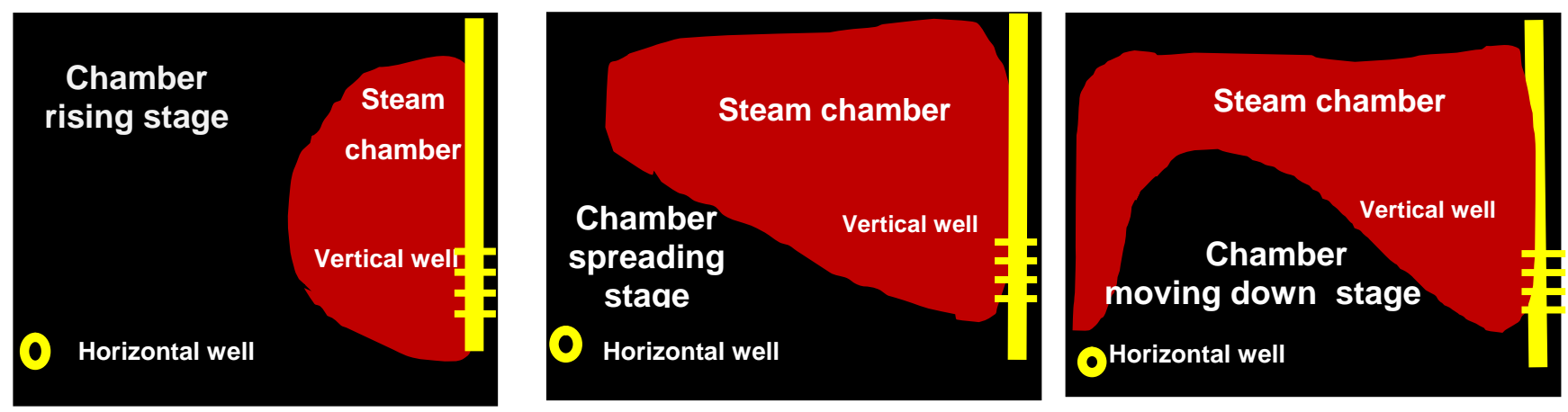

Fig 1 Three stages of steam chamber devlopment

Constuction of numerical simulation model. To study the mechanism and develoment effect of SAGD and SAGP processes, numerical simulation methods are detrimental. In this paper, a typical 1-well-group was selected from D block in Liaohe Oil Field and studied with the utilization of commercial reservoir modeling and simulation software. After historical development matching process, the adaptation of flue gas assisted steam gravity drainage technique is studied.

Phase behavior simlation of flue gas and reservoir oil. A robust equation of state parameters are basics of SAGD and SAGP simulation and was carried out by simulation the phase behavior of gas-oil PVT experimental data (Table 1) under reservoir condition.

\section{Table 1 PVT experimental data}

\begin{tabular}{cccccc}
\hline $\begin{array}{c}\text { GOR } \\
{\left[\mathrm{m}^{3} / \mathrm{m}^{3}\right]}\end{array}$ & $\begin{array}{c}\text { Volume } \\
\text { factor }\left[\mathrm{m}^{3} / \mathrm{m}^{3}\right]\end{array}$ & $\begin{array}{c}\text { Oil density } \\
{\left[\mathrm{g} / \mathrm{cm}^{3}\right]}\end{array}$ & $\begin{array}{c}\text { Degassed oil } \\
\text { density }\left[\mathrm{g} / \mathrm{cm}^{3}\right]\end{array}$ & $\begin{array}{c}\text { Reservoir oil } \\
\text { viscosity }[\mathrm{mPa} \cdot \mathrm{s}]\end{array}$ & $\begin{array}{c}\text { Bubble point } \\
\text { pressure }[\mathrm{Mpa}]\end{array}$ \\
\hline 18.6 & 1.0906 & 0.8856 & 0.9783 & 92 & 10. \\
\hline
\end{tabular}

Flue gas, which is a gas mixture with $12.16 \%$ of $\mathrm{CO}_{2}, 82.44 \%$ of $\mathrm{N}_{2}$ and $4.4 \%$ of $\mathrm{O}_{2}$ is contacted with heavy oil of D block, a small amount of flue gas could be dissolved into oil, with a reduction of oil viscosity and increasment of oil volume. The curves of regression results are shown in Fig 2 with density, viscosity, GOR and volume factors included.
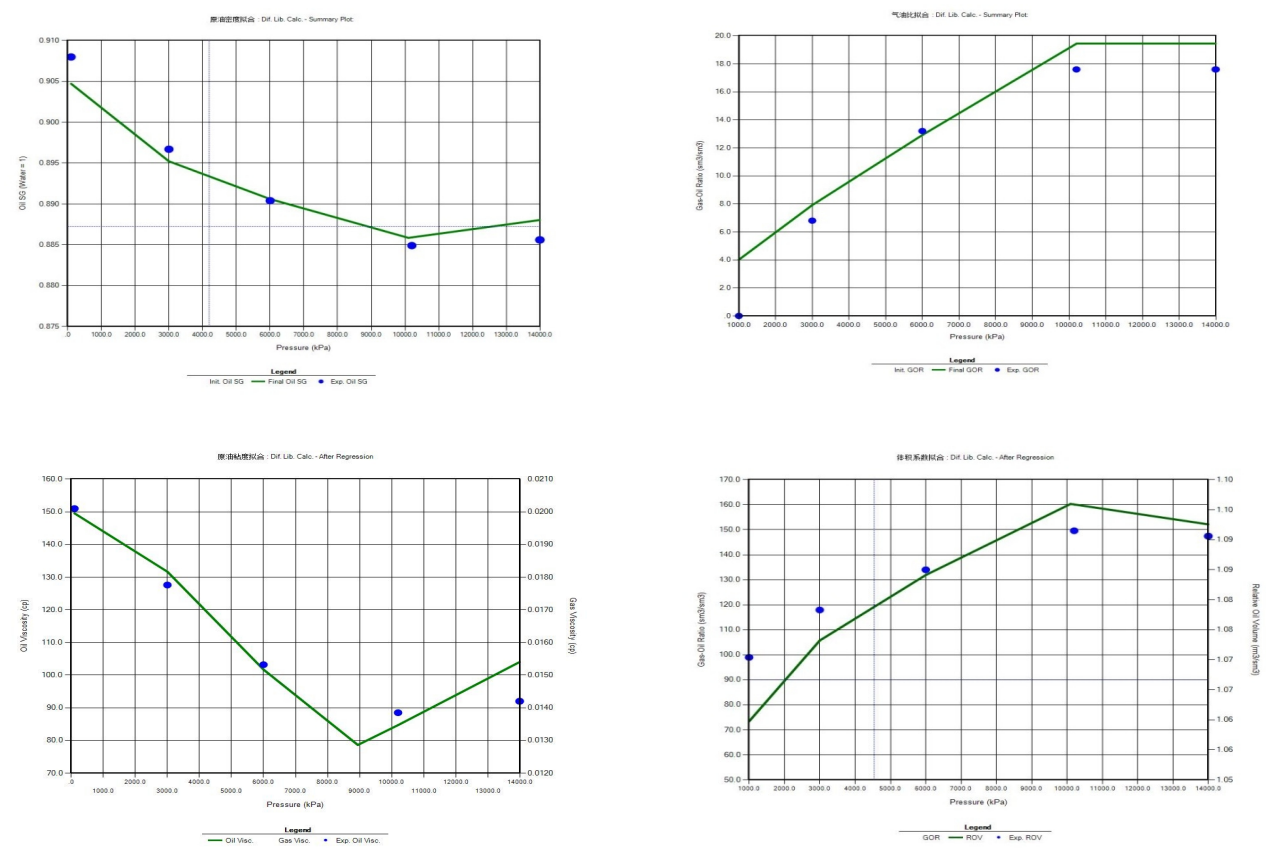

Fig.2 PVT regression curves 


\section{Simulation results}

We observed the property at typical grid cells such as temperature of chamber, composition distribution and production characteristics in different stages. The differences between SAGD and SAGP are well summarized.

Temperature distribution. With flue gas co-injection, steam chamber propagated with a lower vertical speed compared with SAGD, opposite was the horizontal speed. Flue gas was distributed along the cap rock, making a lower heat loss speed. For example, a certain grid cell at a certain time at relatively top of the chamber was selected, the temperature was $248^{\circ} \mathrm{C}$ while the temperature of SAGP was only $48^{\circ} \mathrm{C}$. With steam injection continued, the temperature of SAGP rose to $248^{\circ} \mathrm{C}$ one year later (Fig 3). It was also obvious that both the vertical and horizontal chamber volume expanded.

Chamber temperature of conventional SAGD process is generally $230^{\circ} \mathrm{C} \sim 240^{\circ} \mathrm{C}$, while chamber of SAGP was $30^{\circ} \mathrm{C} \sim 40^{\circ} \mathrm{C}$ lower and so was the cap rock temperature. Then we can draw a conclusion that SAGP can save a portion of steam and decrease the heat loss of the oil reservoir. However, too much flue gas will decrease the temperature of the chamber and even destroy the steam chamber.

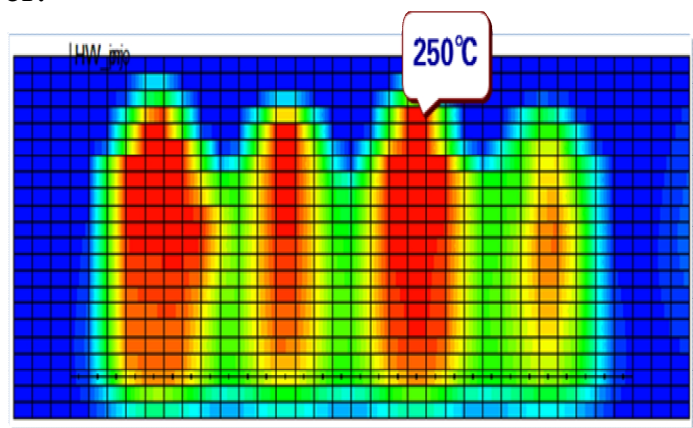

(a) Temperature of SAGD

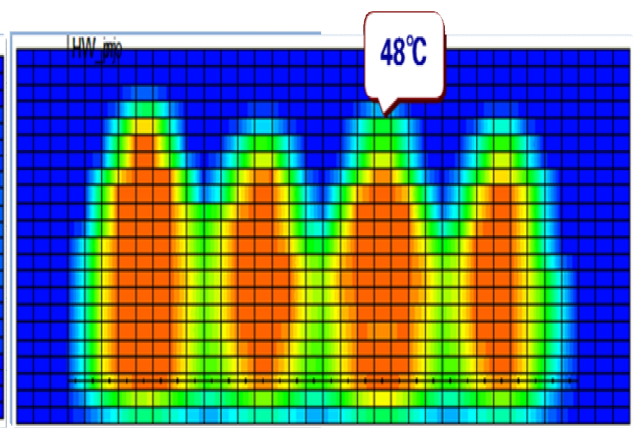

(b) Temperature of SAGP

Fig.3 Temperature profile of simulation model results

Production Characteristics. At early stage, simulation results showed that two SAGP type both had a higher recovery. Total recovery of conventinal SAGD, SAGP and SAGP with gas slug injection were nearly the same 70\% (Table 2). SAGD seemed that it did not gain a higher recovery, however, it had reduced steam injection volume, so that it can save thermal energy and reduce greenhouse gas emission.

Table 2. Three types of recovery

\begin{tabular}{cccc}
\hline \multirow{2}{*}{ Types } & \multicolumn{3}{c}{ Recovery [\%] } \\
\cline { 2 - 4 } & Steam cycling stage & Drainage stage & Total Recovery \\
\hline Conventinal SAGD & 22.8 & 46.3 & 69.1 \\
SAGP & 20.5 & 50.1 & 70.6 \\
SAGP with gas slug & 19.6 & 52.1 & 71.7 \\
injection & &
\end{tabular}

Flue gas distribution. $\mathrm{N}_{2}$, which is the main component in flue gas and is lighter than steam, was tend to spread to the top of chamber until reaching to the cap rock. $\mathrm{N}_{2}$ is also a non-condensate gas and has a higher mobility, so it can spread to the zones where steam can not reach, making a larger sweep efficiency (shown as in Fig 4 with four different times of $\mathrm{N}_{2}$ composition distribution).

For consideration of environmental issues, much flue gas is emitted into atmosphere from steam generators day and night. The sequestrated flue gas of SAGP process can mitigate the greenhouse effect. 


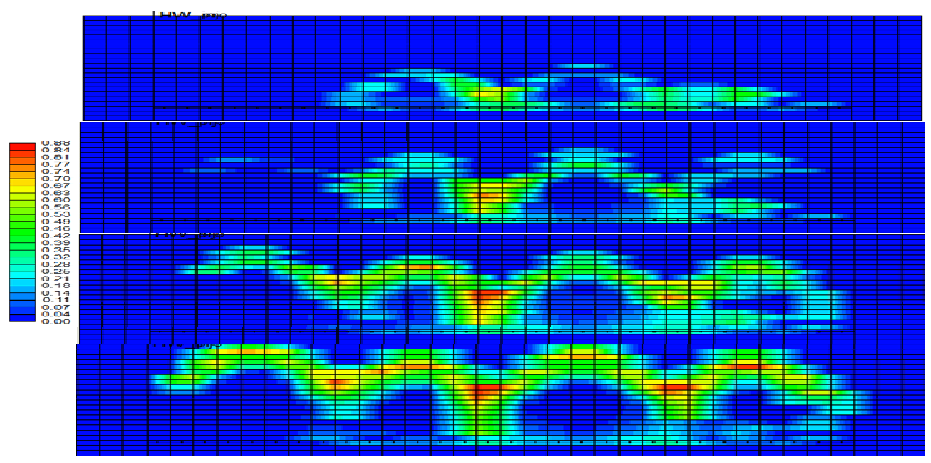

Fig. $4 \mathrm{~N}_{2}$ composition distribution

\section{Conclusions}

(1) Flue gas, which can partially dissovled into heavy oil at reservoir condition, can swell the oil and reduce oil viscosity, increasing heavy oil mobility.

(2) Through observing simulation results, flue gas tended to concentrate at chamber tops untill reaching to cap rock, forming a thermal insulation layer between reservior and overburden rock.

(3) Flue gas could also control the equilibrium of the steam chamber to gain more sweep volume especially in horizontal direction.

(4) For consideration of environmental issues, the underground sequestrated flue gas of SAGP process can mitigate the greenhouse effect and the injection of flue gas can reduce steam volume to save thermal energy.

\section{Acknowledgements}

This work was financially supported by the CNPC academic research and technical development project: "Key technology of recovery and oil/gas ratio improvement of deep and mid-deep heavy oil reservoirs." (2012E-3006).

\section{Literature References}

[1] Z Fang-Li, Z Ying, C Guang-Sheng, Z Li, HU Chang-Hao. 2007. Long-term plan and pilot test deployment of steam flooding and SAGD for Class II and III heavy oil reserves in Liaohe oil province. SPECIAL OIL \&amp; GAS RESERVOIRS, 14(6): 11-16.

[2] Z Liu, M Zhang, D Zhou, Y Sun, H Wang. 2013. Special Oil \&amp; Gas Reservoirs, 20(6): 96-98. [3] LI Zhao-Min, W Yong, LI Bin-Fei, T Lei, Y Jian-Ping. 2010. Dissolubility of flue gas in super-heavy oil. SPECIAL OIL \&amp; GAS RESERVOIRS, 17(5): 84-86.

[4] JI Youjun, C Linsong, L Qicheng, L Zhibo. 2010. Digital experiment on steam and in-condensable gas push for extra heavy oil reservoir. ACTA PETROLEI SINICA, 31(4): 602-606. [5] L Guangyue, L Shangqi, S Pingping, L Yang, L Yanyan. 2016. A new optimization method for steam-liquid level intelligent control model in oil sands steam-assisted gravity drainage (SAGD) process. Petroleum Exploration and Development, 43(2): 275-280. 